\title{
DIREITOS HUMANOS COMO TRUNFOS E A PROIBIÇÃO ABSOLUTA DO USO DE MECANISMOS DE TORTURA PELO DIREITO INTERNACIONAL
}

\section{HUMAN RIGHTS AS TRUMPS AND THE ABSOLUTE PROHIBITION OF TORTURE BY INTERNATIONAL LAW}

Caroline Stéphanie Francis dos Santos Maciel carolinedossantos3@gmail.com

Fabiana de Menezes Soares fabiana.demenezes@terra.com.br

Recebido: 12-6-2018

Aprovado: 5-5-2019

Sumário: 1 Introdução; 2 Direitos humanos como trunfos e as exigências trazidas pelos dois princípios da dignidade; 3 As resistências teóricas ao conceito dworkiniano de direitos humanos e as réplicas de Dworkin; 4 Griffin, Raz e Rawls: alternativas doutrinárias em matéria de direitos humanos; 5 A aplicação do conceito de direitos humanos à controvérsia do uso de mecanismos de tortura em situações emergenciais; 6 Consideraçóes finais; 7 Referências.

\section{Resumo:}

O objetivo deste artigo é analisar algumas definiçôes de direitos humanos, a fim de demonstrar que a de Dworkin é a mais adequada para defender a proibição absoluta do uso de mecanismos de tortura pelo direito internacional. Para tanto, utilizase como técnica metodológica a pesquisa teórica e jurisprudencial e o procedimento metodológico de análise de conteúdo.

\section{Palavras-chave:}

Direitos humanos como trunfos. Ronald Dworkin. Direito Internacional dos direitos humanos. Proibição absoluta da tortura. Violações a direitos humanos.

\section{Abstract:}

The purpose of this paper is to examine some definitions of human rigths, in order to show that Dworkin's theory is the most suitable to argue the absolute prohibition of torture by international law. For that, it applies the theoretical and jurisprudential research as methodological technique and the methodological procedure of content analysis.

\section{Keywords:}

Human rights as trumps. Ronald Dworkin. International Human Rights Law. The absolut prohibition of torture. Human rights violations. 


\section{INTRODUÇÃO}

Em um cenário de grave crise político-social no Brasil e de frequentes violações aos direitos mais básicos dos cidadãos, retomar as discussões sobre os direitos humanos nunca pareceu tão oportuno. Ainda que a atual tendência mundial tenha sido de ascensão ao poder de uma extrema direita com agenda xenófoba, racista, homofóbica e fascista, as restriçóes e violaçóes aos direitos humanos têm sido, como nunca, amplamente reprovadas e têm causado protestos em larga escala pelo mundo afora. Nesse sentido, Raz (2010, p. 321) afirmou que hoje é uma boa época para se fazer discursos sobre direitos humanos.

Mas o que são direitos humanos? Quais são os seus elementos intrínsecos, que os diferenciam dos demais direitos? Não há dúvidas sobre a centralidade e o status diferenciado dado aos chamados direitos humanos, mas como saber quais, dentre os inúmeros direitos existentes, são suficientemente essenciais para serem qualificados como direitos humanos? Algumas respostas a esses questionamentos foram desenvolvidas no decorrer dos séculos, com especial destaque para as teorias de Rawls, de Raz, de Griffin e de Dworkin.

Nesse contexto, este trabalho, fruto de pesquisa teórica e jurisprudencial e através do procedimento de análise de conteúdo, irá percorrer essas conceituaçóes de direitos humanos, para demonstrar que a teoria de Dworkin sobre direitos humanos é a mais adequada para explicar e defender a proibição absoluta do uso de mecanismos de tortura. A aplicaçáo desse conceito abstrato de direitos humanos em uma violação prática tão recorrente no Brasil (sobretudo por forças policiais e tropas de choque em comunidades carentes e favelas, especialmente na "luta contra o tráfico de drogas") e no mundo todo (principalmente na "luta contra o terrorismo") ainda é uma discussão atual e relevante, pois a ideia de que deve haver uma flexibilização dos direitos humanos em casos tidos como emergenciais ainda é, infelizmente, muito defendida. É contra esse tipo de pauta que este artigo vai se voltar, para defender que até mesmo em situaçóes nas quais o suposto bem-estar coletivo seria protegido por tais violaçóes, ainda assim, esses direitos são tão importantes que devem ser preservados, atuando como trunfos contra as justificativas para a ação política.

\section{DIREITOS HUMANOS COMO TRUNFOS E AS EXIGÊNCIAS TRAZIDAS PELOS DOIS PRINCÍPIOS DA DIGNIDADE}

Antes de tudo, é importante trazer à baila o questionamento sobre o uso das expressóes "direitos humanos" ou "direitos do homem", que podem se mostrar excludentes na perspectiva dos seus destinatários, na medida em que, apesar da segunda denominação, inclui também os direitos das mulheres (SOARES, 2016, p. 38) e, conforme entendimentos jurisprudenciais e doutrinários mais recentes, também atuaria na defesa dos animais e da natureza (SOARES, 2016, p. 35). Por muito tempo, os direitos humanos eram formalmente conferidos a apenas alguns sujeitos privilegiados, homens, ocidentais, brancos, o que significava a retirada da humanidade de alguns (como os negros escravos) e da cidadania política de outros (como as mulheres), configurando-se uma grande mitigação do alcance da Declaração dos Direitos do Homem e do Cidadão (SOARES, 2016, p. 50). Esse é um ponto relevante até hoje, na medida em que, apesar da abrangência mais universalista dada aos direitos humanos, materialmente, ainda há muito desrespeito seletivo de direitos humanos, por razóes de gênero, etnia, nacionalidade. 
Por isso, o termo "direitos fundamentais" pode soar mais inclusivo, no que tange aos detentores. Optou-se aqui, contudo, pelo uso da expressão "direitos humanos", pelo seu tradicional emprego no contexto internacional e pelo caráter constitucional geralmente associado a "direitos fundamentais", mantendo em mente que a expressão foi usada neste artigo da forma mais abrangente possível quanto aos seus destinatários, incluindo especialmente as minorias e os diferentes.

Apesar de, como já ressaltado, os direitos humanos estarem bem longe de serem universais e de não se restringirem a uma perspectiva antropocentrista, essa expressão é corriqueiramente usada para fazer referência àqueles direitos mais básicos, conferidos aos indivíduos enquanto seres humanos. Por isso, a mais grave acusação que um Estado pode sofrer é a de que violou direitos humanos (DWORKIN, 2006, p. 28). Muitas vezes são usados fundamentos jurídicos para se demonstrar tais violaçóes, mas, como demonstra Dworkin (DWORKIN, 2006, p. 27), as discussôes sobre direitos humanos são antes morais do que jurídicas, uma vez que envolvem compreender o que é moralmente assegurado às pessoas terem e exigirem, uns dos outros, dentro de uma comunidade política ${ }^{1}$.

Isso significa que há uma dimensão simbólica dos direitos humanos, que é mais profunda que o direito e vai "muito além do que está positivado nas normativas, princípios e procedimentos presentes no ordenamento jurídico, dado que procura compreender o contexto mais amplo e profundo em que se inserem os conflitos de direitos" (CLÍNICA DE DIREITOS HUMANOS DA UFMG, 2015, p. 11-12). A dimensão moral e política dos direitos humanos é, portanto, essencial para a sua efetivação e a legislação atua nisso de forma simbólica, ao oferecer suporte político, social e moral para a conduta dos indivíduos, contribuindo para a sua conformação a tais valores (CLÍNICA DE DIREITOS HUMANOS DA UFMG, 2015, p. 12).

Se os direitos humanos se encontram na seara da moralidade política, a compreensão de seu conceito passa pela definição de direitos políticos, em contraposição aos chamados direitos jurídicos. A ideia de direitos políticos é melhor entendida como "trunfos que atuam contra justificativas de ação política” (DWORKIN, 2011, p. 329), justificativas estas que os sacrificariam em prol de ações que visem aumentar o bem-estar da comunidade como um todo (DWORKIN, 1985, p. 153). Desse modo, direitos políticos são aqueles "interesses individuais que são tão importantes que seria errado - moralmente errado - para a comunidade sacrificá-los apenas para se garantir um benefício geral” (DWORKIN, 2006, p. 31).

Mas qual a justificativa para que um direito individual prevaleça em contraposição a uma açấo política socialmente desejável? O fundamento disso está na interpretação harmônica e complementar dos dois princípios da dignidade humana desenvolvidos por Dworkin (2011, p. 330), a saber, a igual consideração por cada vida humana - a igualdade - e o igual respeito pela responsabilidade de cada pessoa de identificar e buscar o sucesso em sua própria vida - a liberdade. Assim, as exigências trazidas pelos dois princípios da dignidade irão determinar quais são os direitos políticos, isto é, quais são os direitos que atuam como trunfos contra açóes políticas que aumentariam o bem-estar geral. As pessoas têm, portanto, direito político a qualquer proteção necessária ao respeito dos dois princípios da dignidade.

$1 \quad$ Nesse sentido, Dworkin afirma que a moralidade política, ao contrário da moralidade pessoal e da ética, é melhor compreendida a partir da noção de direitos e não de responsabilidades (DWORKIN, 2011, p. 327). 
Compreendida a noção básica de direito político, é importante diferenciá-la da ideia de direito jurídico. Segundo Dworkin (2011, p. 331), a relação entre direito político e direito jurídico é uma relação entre gênero e espécie, sendo que a categoria direito jurídico é um tipo especial de direito político que pode ser institucionalmente exigido pelas vias judiciais. A partir dessas duas concepçóes, Dworkin esclarece o que são direitos humanos e como eles diferem dos direitos jurídicos e dos demais direitos políticos, categoria da qual eles fazem parte.

Bem verdade, os direitos humanos também atuam como trunfos e, portanto, são direitos políticos que, de alguma forma, são ainda mais especiais e importantes. Isso porque a noção de direitos humanos evoca um direito a uma atitude: o direito de ser tratado como um ser humano cuja a dignidade importa de maneira fundamental (DWORKIN, 2011, p. 335).

É interessante notar que o conceito de direitos humanos como trunfos contra justificativas de ação políticas pode ser aplicado para a defesa dos direitos dos animais. É possível compatibilizar o tratamento de "pessoa jurídica" aos animais (ao invés de "coisa") (SOARES, 2016, p. 52), postura defendida pela organização não governamental NonHuman Rights Project ${ }^{2}$, com a interpretação dos dois princípios da dignidade de Dworkin. Seria moralmente errado sacrificar, abusar, explorar animais para se garantir um bem coletivo e, assim, caberia dizer que os direitos humanos ou os direitos fundamentais na perspectiva dworkiniana podem abarcar a proteção dos animais. Nesse sentido, a teoria de direitos humanos de Dworkin poderia embasar os habeas corpus impetrados pelo NonHuman Rights Project em prol da liberdade de animais presos contra a sua vontade, por se tratarem de seres autônomos e com vontade própria, fazendo jus à proteção dos direitos humanos.

Dessa forma, respeitar os direitos humanos significa se importar com a dignidade humana (ou, de forma mais abrangente, dos seres vivos). Ao revés, violar os direitos humanos significa demonstrar desprezo ou indiferença pela dignidade. Em outras palavras, a diferença entre uma violação a um direito político genérico e uma violação a um direito humano básico reside na diferença trazida por Dworkin (2011, p. 335) entre um ato de engano e um ato de desprezo, baseada na noção de legitimidade do governo e cujo critério é interpretativo. É possível que um governo respeite os direitos humanos mesmo quando falha na consecução de direitos políticos concretos, desde que essa falha seja motivada por um ato de engano, havendo um esforço interpretativo, ainda que equivocado, dos dois princípios da dignidade (DWORKIN, 2006, p. 35). Ao revés, algumas açóes políticas não podem ser justificadas, a não ser por motivos torpes que demonstram completo desprezo pela vida humana. Nesses casos, há um ato de desprezo por parte do governo e a violação aos direitos humanos é inegável.

Para esclarecer a diferenciação dada acima, Dworkin (2011, p. 336-337) enumera alguns exemplos, dentre eles a prática de tortura, que seria uma nítida violação de direitos humanos, por desrespeito tanto ao primeiro princípio da dignidade quanto ao segundo ${ }^{3}$. Quando um Estado se utiliza de mecanismos de tortura, ele demonstra um ato de desprezo

2 NONHUMAN RIGHTS PROJECT. Portal da organização não-governamental "Nonhuman Rights Project". Disponivel em: https://www.nonhumanrights.org/. Acesso em: 19 jun. 2017.

3 Isso porque praticar tortura demonstra uma grave desconsideração pela vida humana (desrespeito ao primeiro principio da dignidade), bem como um considerável desrespeito pela responsabilidade pessoal de cada individuo (violação ao segundo), por não admitir opiniões políticas diversas, no caso da tortura motivada por fins políticos. 
pela vida e dignidade humanas, bem como pela responsabilidade pessoal, no caso de, por exemplo, torturar inimigos políticos, pelo fato de terem opinióes políticas opostas às governamentais. Não há nenhuma interpretaçáo possível dos dois princípios da dignidade que autorize o uso de tortura e, por isso, qualquer alegação de "equívoco de boa fé" deste Estado seria desarrazoada.

Da mesma forma, a escravidão é uma prática que inegavelmente fere os dois princípios da dignidade e configura um brutal desrespeito aos direitos humanos, sendo uma barbárie não apenas histórica, mas até hoje praticada. Antes mesmo da abolição da escravidão nas suas colônias, em 1772, foi julgado no Reino Unido o caso Somerset v. Stewart (COURT OF KING'S BENCH. Somerset v Stewart, 98 ER 499, 14 May 1772) que se tornou um marco paradigmático para a jurisprudência britânica à época, na medida em que decidiu que um escravo não poderia ser removido à força do território britânico, pois isso fere os princípios da common law e os direitos garantidos pela Magna Carta. Apesar do contexto histórico aparentemente distante desse caso, o tráfico de pessoas para fins de trabalho forçado, de trabalho em condiçóes análogas à escravidão e de exploração sexual é um problema global contemporâneo. A International Labour Organization (ILO) estima que, no período de 2002 a 2011, cerca de 20,9 milhōes de pessoas foram vítimas de trabalho forçado no mundo (INTERNATIONAL LABOUR ORGANIZATION, 2012, p. 13). Segundo o Global Report on Trafficking in persons de 2016 do Escritório das Naçóes Unidas sobre Drogas e Crime (UNODC), entre 2012 e 2014, 54\% das vítimas de tráfico humano foram para exploração sexual e $38 \%$ para trabalho forçado (UNITED NATIONS OFFICE ON DRUGS AND CRIME, 2016, p. 6). Além disso, a grande maioria das vítimas de tráfico de pessoas são mulheres $(51 \%)$ e crianças (28\%) (UNITED NATIONS OFFICE ON DRUGS AND CRIME, 2016, p. 7).

Por outro lado, não se pode dizer com a mesma convicção que a existência de leis contra discursos de ódio é uma violação a direitos humanos, no caso à liberdade de expressão. Em alguns países, como na Alemanha e no Brasil, proíbe-se o uso de determinados discursos de cunho discriminatório, enquanto em outros, como nos EUA, a liberdade de expressão náo poderia ser restringida dessa forma. Alguns poderiam alegar que tal proibição violaria o direito à liberdade de expressão e, por isso, o segundo princípio da dignidade; no entanto, é sim possível construir uma interpretação compatível com os dois princípios da dignidade para justificar esse tipo de lei. Ainda que alguns entendam se tratar de um ato de equívoco em matéria de direitos políticos, não se configuraria um ato de desprezo e, portanto, náo poderia se alegar que a existência de leis dessa natureza seria uma violaçấo dos direitos humanos.

Desse modo, a constataçáo de que houve desrespeito aos direitos humanos, segundo a teoria de Dworkin, requer um juízo interpretativo do caso concreto, para verificar se a conduta demonstra desprezo pela dignidade humana, a partir da aplicaçáo de seus dois princípios derivativos, a igualdade e liberdade. Não sendo possível a compatibilização da conduta com tais princípios, trata-se de uma afronta aos direitos humanos. Caso exista uma justificativa compatível com tais princípios para a conduta, não se configura violação de direitos humanos, no máximo, um ato de engano. Mas a natureza interpretativa do conceito de direitos humanos de Dworkin não deixaria espaço para todo tipo de argumentação? Como ter certeza que se está diante de uma afronta a direitos humanos em casos de difícil solução? Esses são alguns questionamentos levantados por críticos à teoria de Dworkin e que são abordados a seguir. 


\section{As resistências teóricas ao conceito dworkiniano de direitos humanos e as réplicas de Dworkin}

De acordo com Sloane (2010, p. 981), a explicação de Dworkin acerca dos direitos humanos é muito vaga, abstrata e conceitualmente indeterminada, na medida em que os dois princípios da dignidade não oferecem orientação epistemológica quanto aos problemas concretos de mais difícil solução na seara dos direitos humanos. Em razão disso, mesmo que se adote os dois princípios da dignidade, a sua aplicação, de boa-fé, por duas pessoas diferentes, pode gerar resultados radicalmente diferentes em matérias controversas de direitos humanos (SLOANE, 2010, p. 981).

Em réplica a Sloane, Dworkin (2010, p. 1083) aponta, preliminarmente, que o autor confunde incerteza com indeterminação. Incerteza é uma posição omissiva decorrente da falta de convicção profunda sobre determinado assunto, em razão da existência de argumentos igualmente fortes contra e a favor de uma posição. Por sua vez, indeterminação é uma afirmação positiva de que não existe resposta correta para aquela controvérsia, sendo, portanto, uma forma de ceticismo (DWORKIN, 2011, p. 91-92). Desse modo, a teoria de direitos humanos de Dworkin baseia-se na existência de uma resposta correta, em oposição ao ceticismo, ainda que os aplicadores não tenham certeza de qual é essa resposta.

No entanto, Dworkin (2010, p. 1083) admite que a sua argumentação sobre direitos humanos é realmente abstrata, mas apenas na medida em que toda fundamentação teórica sobre direitos humanos também o é. Inclusive, ele acredita que o teste oferecido por Sloane, qual seja, a de se determinar os direitos humanos através da reflexão sobre quais são os direitos que as pessoas precisam, não é menos abstrato e não causa menos desacordos do que o teste por ele oferecido. Desse modo, a própria teoria de Sloane, como toda teoria de direitos humanos, não supera esse segundo tipo de objeção que ele aponta.

A outra crítica de Sloane (2010, p. 997) é que, apesar de haver muita discordância quanto a questóes morais e éticas fundamentais, a teoria de Dworkin se basearia em uma moral fundacionista universal. Isso porque o fundamento último da teoria de direitos humanos de Dworkin repousa na verdade e na universalidade da seguinte proposição abstrata: que a dignidade humana exige igual consideração pelas vidas humanas e igual respeito pela responsabilidade pessoal. No entanto, a ordem internacional é empiricamente caracterizada por um pluralismo cultural, político, jurídico e moral, o que iria de encontro à ideia de um fundamento moral universal. Por isso, a teoria de Dworkin seria impraticável no universo do Direito Internacional.

Não obstante, para Dworkin (2010, p. 1084), é impossível fugir disso. Ainda que declarar o fundamento por detrás dos direitos humanos não seja a melhor estratégia para convencer países a assinarem tratados sobre o tema, não se pode esquivar daquilo que se acredita ser a verdade; um embasamento teórico em direitos humanos é necessário antes de se discutir e de se tentar negociar, na prática, acordos e tratados em direitos humanos.

Foi apontada ainda por West (2010, p. 821) outra crítica à teoria de direitos humanos de Dworkin. Ela não concorda com a metáfora dos direitos humanos como trunfos, pois acredita que gera como resultado consequências negativas e, em razão disso, deve ser abandonada. O conceito de direito como trunfo impede que se considere os prejuízos trazidos aos indivíduos e à coletividade pela proteção de um direito individual assim compreendido. A autora acredita que Dworkin leva os direitos a sério, mas não faz o mesmo com as políticas coletivas, na medida em que seu enfoque é completamente voltado aos primeiros, em desconsideração às segundas. 
Segundo West (2010, p. 823-825), o raciocínio de direitos como trunfos faz com que seja juridicamente permitidas algumas práticas individuais indesejáveis, tais como: o porte de armas e a possibilidade de levá-las a uma manifestação política ou ainda os rituais de sacrifício de animais por razões espirituais. Caso não se adote a ideia de direitos como trunfos, essas práticas poderiam ser crimes, com a finalidade de se proteger a comunidade dos potenciais prejuízos por elas trazidos. Dessa forma, a adoção do conceito de direitos como trunfos seria prejudicial, na medida em que oculta os danos trazidos à coletividade pelo exercício de alguns direitos individuais e que não permite o sopesamento de interesses como método de decisão sobre qual curso de ação deve ser adotado. Ademais, essa autora ainda aponta que o conceito de Dworkin estimularia um ambiente de valorização do individualismo em contraposição à noção de comunitarismo, no qual o indivíduo que exerce seu direito contra a máquina estatal é tido como vítima, o que oculta os males coletivos trazidos pelo exercício desse direito individual (West, 2010, p. 827).

Dworkin (2010, p, 1070) respondeu aos argumentos de West afirmando que, na verdade, a insatisfação dela não seria com a metáfora dos direitos políticos como trunfos em si, mas sim com a aplicação desse raciocínio por certos grupos quanto a certos direitos, com os quais ela não concorda. Dessa forma, ele aponta que isso apenas traz à tona a necessidade de uma reflexão quanto a quais direitos são suficientemente importantes para atuarem como trunfos e, portanto, para serem considerados direitos políticos. Ao invés de se dispensar o conceito de direitos como trunfos, a autora deveria evidenciar o porquê de alguns direitos não se encaixarem nessa categoria e, assim, não serem direitos humanos genuínos, tal qual o direito dos cidadãos à posse de armas de fogo ou o sacrifício de animais em rituais espirituais. Como o conceito de Dworkin é interpretativo, é necessário a construção de uma argumentação racional embasada dos dois princípios da dignidade para a defesa do status de direitos humanos de um certo direito; assim, é possível perceber que a proteção dos animais contra eventuais abusos se encaixa muito mais na definição dworkiniana de direitos humanos do que, por exemplo, um suposto direito dos seres humanos de sacrificá-los em prol da liberdade religiosa.

Conforme exposto nesta seção, Dworkin contrapôs sólidas objeçôes aos argumentos levantados contra a sua teoria de direitos humanos. Resumidamente, contra o questionamento de que o conceito interpretativo de direitos humanos por ele proposto seria muito vago e, por isso, deixaria espaço para diversos cursos argumentativos, Dworkin defende a sua teoria da única resposta certa (1999, p. 99). Para cada caso, inclusive os difíceis, o direito tem uma solução correta, que deve ser buscada pelo intérprete a partir da interpretação harmônica dos dois princípios da dignidade humana. A noção de verdade em juízos interpretativos de Dworkin deriva do seu conceito de direito como integridade, de tal forma que os princípios de um sistema jurídico não conflitam entre si e nem se contradizem, mas sim se apoiam mutuamente (1999, p. 99). Dessa forma, a melhor interpretação é aquela na qual os princípios se sustentam uns aos outros, como numa rede de valores (DWORKIN, 1999, p. 294). Esse é, portanto, o referencial dworkiniano para a solução dos casos de afronta a direitos humanos, assim como para todos problemas jurídicos.

\section{Griffin, Raz e Rawls: alternativas doutrinárias em matéria de direitos humanos}

Esboçados os elementos centrais da concepção de direitos humanos de Dworkin e as críticas à sua teoria, passa-se agora à análise de doutrinas alternativas para justificadamente 
concluir, ao final, se o caminho teórico tomado por Dworkin é a melhor escolha para a efetivação dos direitos humanos.

Uma doutrina substantiva de direitos humanos pode ser caracterizada por ser aquela cuja classificação dos direitos como direitos humanos se baseia no seu conteúdo substantivo e não meramente operacional ${ }^{4}$. Uma das mais sofisticadas teorias que se encaixam nessa categoria foi desenvolvida por James Griffin. Para Griffin (2010, p. 345), "direitos humanos são as proteções do nosso status humano [...] são as proteções da nossa entidade normativa, do que eu chamei de 'humanidade'." Assim, respeitar a humanidade significa garantir, por exemplo, bem-estar, liberdade e autonomia; como estas são proteçóes de humanidade, são, portanto, direitos humanos. Mas, como a noção de humanidade é demasiadamente indeterminada, o segundo fundamento dos direitos humanos em Griffin são os seus aspectos práticos, na terminologia própria do autor. A ideia de aspectos práticos dos direitos humanos, como a própria expressão diz, refere-se às consideraçóes de como os seres humanos e a sociedade funcionam na realidade (GRIFFIN, 2010, p. 246).

A crítica de Dworkin ${ }^{5}$ à Griffin é que ao basear os direitos humanos nas condiçóes de humanidade (autonomia, bem-estar e liberdade), o autor necessariamente comete um desses dois equívocos: se as condiçóes de humanidade forem limitadas, são facilmente alcançadas, em quaisquer circunstâncias (inclusive considerar que um escravo tem liberdade, por exemplo). Se, por outro lado, se exige um alto grau de liberdade, bem-estar e autonomia para se preencher as condiçóes de humanidade, a diferença entre direitos humanos e direitos políticos se esvai (RAZ, 2010, p. 325).

Em contraposição à chamada doutrina tradicional de direitos humanos ${ }^{6}$, Raz defende a mesma teoria anteriormente defendida por Rawls e que, segundo ele, diferentemente da clássica, é efetivamente relacionada à prática de direitos humanos. Para Rawls:

Direitos humanos são a classe de direitos que desempenha um papel especial em um razoável Direito dos Povos: eles restringem as razóes justificadoras para guerra e seu desenrolar e especificam limites para a autonomia interna de um regime (1999, p. 79).

A abordagem rawlsiana tem caráter reducionista, na medida em que a lista de direitos que consegue cumprir os requisitos trazidos por Rawls é bem menor do que aquela trazida, por exemplo, em diversos tratados e declaraçóes de direitos humanos. Mas, à contramão das críticas, alguns autores defendem que isso seria um ponto positivo, pois seria mais fácil de alcançar consenso no Direito Internacional com um rol menor de direitos humanos, bem como traria ganhos em termos de implementação (MACLEOD, 2006, p. 135). Quanto ao primeiro ponto, devido ao elevado pluralismo cultural existente na ordem internacional, uma relação de vários direitos humanos dificilmente alcançaria um consenso mais abrangente. Com base nesse argumento pragmático, seria mais positivo dar o nome de direitos humanos apenas àqueles direitos mais básicos, sob pena de a adesão dos países a tratados que versem sobre o tema ser reduzida. Já em termos de implementação, Rawls defende que, em caso

$4 \quad$ Como assevera Griffin, a sua teoria tem "mais elementos substantivos" do que, por exemplo, a de Dworkin, mas não chega a ser puramente substantiva, havendo também implicações de cunho operacional (GRIFFIN, 2010, p. 342).

5 Dworkin traz essa crítica na nota de rodapé 5 e é a mesma feita por Raz à Griffin (DWORKIN, 2011, p. 335).

6 Raz denomina de doutrina tradicional dos direitos humanos as teorias de Alan Gewirth e de James Griffin (2010, p. 323-324); contudo, Griffin discorda dessa classificação (GRIFFIN, 2010, p. 345). 
de violaçôes a direitos humanos em uma sociedade, é permitida a intervenção de outros Estados nos assuntos internos do Estado violador, a fim de que haja ao menos uma redução dessas violações (MACLEOD, 2006, p. 137). A ideia de intervenção internacional só seria admissível caso o rol de direitos humanos seja reduzido, a ponto de incluir táo somente os direitos mais básicos e fundamentais dos seres humanos.

$\mathrm{Na}$ esteira rawlsiniana, Raz (2010, p. 328) compreende como "direitos humanos os direitos que estabelecem limites para os Estados soberanos", de tal forma que em caso de violações, torna-se possível a tomada de medidas pela ordem internacional para fazer com que elas se cessem. Isso não significa, como assevera Raz (2010, p. 328), que a sua compreensão de direitos humanos se restringe a direitos que podem ser exercidos em face de Estados ou até mesmo aqueles exigíveis apenas no contexto internacional. Obviamente, direitos humanos podem ser exercidos contra outros indivíduos ou em face de instituiçóes de toda natureza. $\mathrm{O}$ argumento de Raz é, na verdade, que o caráter distintivo daqueles direitos denominados de direitos humanos é o fato de que a sua violação confere razóes justificadoras para aplicação de sançóes de toda ordem na seara internacional.

Desse modo, tanto a explicação de Rawls quanto a de Raz se centram na ideia de que, nas palavras de Dworkin (2011, p. 333), os direitos humanos são direitos que atuam como trunfos contra a soberania nacional de um Estado. O elemento distintivo entre os dois autores seria, segundo o próprio Raz (2010, p. 328), o fato de que para Rawls a intervenção motivada por violação de direitos humanos seria tão somente de natureza militar, ao passo que para Raz poderia ser qualquer tipo de intervenção, desde que seja uma medida que, em condiçóes normais, não seria permitida na ordem internacional, por configurar uma violação da soberania nacional de um Estado.

Analisando tal teoria, Dworkin (2011, p. 333) aponta que essa conceituação é extremamente restrita, resultando no rebaixamento de diversos direitos humanos previstos em declaraçóes e tratados internacionais, cujas violaçôes não justificariam intervençóes de qualquer natureza a países soberanos. Essa mesma crítica é feita por Griffin (2010, p. 342), que acrescenta que até mesmo o papel dos direitos humanos é restringido pela teoria rawlsiana, se resumindo a fornecer razóes para a guerra e a estabelecer as condiçóes nas quais um Estado pode intervir coercitivamente em outro. Essa restrição não seria positiva, na medida em que, na prática, o reconhecimento de todos esses direitos como direitos humanos é um instrumento valioso na luta por conquistas sociais no mundo todo (GRIFFIN, 2010, p. 334).

Diante do exposto, de um lado, a teoria de Griffin tende a ser muito abrangente e a incluir no rol de direitos humanos quaisquer direitos, esvaindo a importância do conceito; de outro, as teorias de Rawls e de Raz são muito restritivas e colocam requisitos muito elevados para a qualificação de um direito como direito humano, o que prejudica a luta pelo reconhecimento de diversos direitos básicos, inclusive das mulheres, das minorias étnicas e dos animais, como direitos humanos. Por isso, conclui-se que a teoria dworkiniana, dentre as apresentadas, ainda parece ser a melhor opção na busca pela efetivação de tais direitos na ordem internacional e também internamente nos mais diversos ordenamentos jurídicos. Reconhece-se, contudo, a limitação geográfica de sua teoria, elaborada em um contexto ocidental. A heterogeneidade cultural global deve ser respeitada, não se buscando uma padronização ou propagação dos valores e padróes ocidentais de forma automática e irrefletida a contextos culturais muito diversos. Ainda assim, há um comprovado valor teórico do conceito de Dworkin para a defesa dos direitos humanos; passa-se, por isso, à sua aplicação na problemática acerca do uso de mecanismos de tortura em situaçóes 
emergenciais, para se determinar se, a teoria dworkiniana autoriza esse uso ou o rechaça, dando substrato teórico à sua proibição absoluta na ordem internacional.

\section{A aplicação do conceito de direitos humanos à controvérsia do uso de mecanismos de tortura em situações emergenciais}

Como bem lembra Dworkin (2011, p. 336), o direito de não ser torturado ocupa, há muito tempo, o primeiro lugar no rol de direitos humanos, sendo, inclusive, o paradigma de todos eles. Isso porque a tortura é "a mais profunda violação possível da dignidade de um ser-humano" (SUSSMAN, 2005, p. 2), resultando na aniquilação da humanidade da vítima e do torturador (SUSSMAN, 2005, p. 2). Em razão disso, o Direito Internacional estabelece a proibição absoluta do uso de tortura e de outros tratamentos ou penas cruéis, desumanos ou degradantes. ${ }^{7}$ Apesar de tudo isso, essas práticas ainda são amplamente utilizadas em diversos países, seja em ditaduras, em face de opositores políticos ou até mesmo em democracias, justificadas pela "guerra contra o terrorismo" ou ainda a "guerra contra o narcotráfico".

Preliminarmente, é importante serem fixados parâmetros gerais para a definição do que se configura como tortura. Nos termos do art. $1^{\circ}$ da Convenção da $\mathrm{ONU}^{8}$ contra tortura, o conceito de tortura envolve três elementos centrais (NOWAK, 2006, p. 817): i) a severidade da dor ou sofrimento infligido, que pode ser físico ou mental, sendo que a tortura psicológica é tấo devastadora quanto a física; ii) o dolo, a intencionalidade da conduta; iii) um fim ou propósito determinado da prática, tais como: a obtenção de informaçóes ou de confissão, a punição por alguma conduta, a coação, por razões discriminatórias, dentre outras. Alguns autores ${ }^{9}$ incluem um quarto elemento: a vulnerabilidade ou submissão completa da vítima; nesse sentido, só seria possível a prática de tortura quando a vítima está sob controle completo de outrem, sem qualquer chance de resistência. ${ }^{10}$

O grande elemento que diferencia a tortura de outros tratamentos cruéis, desumanos ou degradantes é a existência de um propósito específico na prática de tortura ${ }^{11}$. Nessa abordagem, o uso de mecanismos agressivos de interrogação de suspeitos de terrorismo ou de narcotraficantes configura como tortura, por terem como propósito específico, em regra, a obtenção de informações ou de confissão.

7 A Convenção contra a tortura e outros tratamentos ou penas cruéis, desumanos ou degradantes foi adotada pela ONU em 1984, aprovada pelo Congresso brasileiro pelo Decreto Legislativo n 4/1989 e promulgada pelo Decreto n 40/1991.

8 ORGANIZAÇÃO DAS NAÇÕES UNIDAS. Convenção contra a tortura e outros tratamentos ou penas cruéis, desumanos ou degradantes. 10 dez. 1984. Disponivel em: http://www.ohchr.org/Documents/ Professionallnterest/cat.pdf. Acesso em: 15 mar. 2017.

$9 \quad$ Ibid, p. 832-33; SUSSMAN, David. What's wrong with Torture?, Philosophy \&t Public Affairs, v. 33, n. 1, 2005 , p. 6.

10 Esse foi o fator determinante para a decisão no Caso Hajrizi Dzemajl v. Yugoslavia (UN COMMITEE AGAINST TORTURE. Hajrizi Dzemajl v. Yugoslavia, Communication no 161/2000, U.N. Doc. CAT/C/29/D/161/2000, 21/11/2002. Disponivel em: http://hrlibrary.umn.edu/cat/decisions/161-2000. html. Acesso em: 15 mai. 2017).

11 Essa foi a abordagem utilizada pela Comissão Europeia de Direitos do Homem no paradigmático Caso grego, de 1969 (EUROPEAN COMMISSION ON HUMAN RIGHTS. Greek Case, Commission Report of 5 November 1969, Yearbook 12, 15 abr. 1970. Disponivel em: hudoc.echr.coe.int/app/conversion/pdf/?library=ECHR\&tid=00173020\&tfilename=001-73020.pdf. Acesso em: 20 abr. 2017). 
Tendo em vista os elementos para a definição de tortura acima esboçado, ressalta-se que a proibição absoluta do uso de mecanismos de tortura é trazida por costume internacional e, portanto, vincula todos os Estados, independentemente da ratificação de tratados ou convençóes, bem como foi endossada por diversos dispositivos jurídicos internacionais ${ }^{12}$. Nos termos do Comentário Geral no 2 emitido pelo Comitê contra a tortura da ONU ${ }^{13}$, nenhuma circunstância excepcional de qualquer natureza pode ser invocada por um Estado para justificar atos de tortura ou tratamentos cruéis, desumanos ou degradantes. Essa é uma obrigação não-derrogável, trazida pelo art. 2 da Convenção contra a tortura e outros tratamentos ou penas cruéis, desumanos ou degradantes, que deve ser seguida pelos Estados em qualquer território sob sua jurisdição, inclusive em instalaçóes no estrangeiro.

Apesar de sua proibição pelo Direito Internacional de forma expressa e absoluta e da ratificação da Convenção contra a Tortura e Outros Tratamentos ou Penas Cruéis, Desumanos ou Degradantes por 155 países, a tortura continua sendo uma prática difundida mundialmente. Nos últimos cinco anos, a Anistia Internacional (Amnesty International), organização não-governamental que luta pela defesa dos direitos humanos, constatou a prática de tortura e de outros tratamentos desumanos em pelo menos 141 países, de todas as regiôes, num total de três quartos do globo, seja de forma sistemática e recorrente ou como medida emergencial e excepcional ${ }^{14}$.

Por isso, é relevante discutir se há substrato teórico para a relativização no uso da tortura em casos excepcionais. Assim, passa-se agora a discutir a aplicação do conceito de direitos humanos de Dworkin para se determinar a juridicidade do uso mecanismos de tortura em cenários emergenciais, tal como o exemplo clássico da bomba relógio colocada por um terrorista e do uso de tortura para a obtenção de suas informaçóes, evitar o ataque e, assim, salvar vidas inocentes.

Conforme já dito, um direito político é um trunfo contra uma ação política coletiva, ainda que ela gere bem-estar. Assim, preliminarmente, o direito de um indivíduo de não ser torturado, entendido como pelo menos um direito político, atuaria como trunfo contra, por exemplo, contra uma decisão política de torturar para salvar vidas inocentes de um ataque terrorista ou ainda de torturar para obter informaçóes sobre a localização de terroristas ou de traficantes. Para se concluir se realmente o direito de não ser torturado é um direito político, é preciso analisar e interpretar os dois princípios da dignidade, de tal forma que se determine se um ato de tortura sacrificaria ao menos um desses princípios.

Nos termos do primeiro princípio da dignidade, o princípio igualdade, isto é, da igual consideração por cada vida humana, o sistema de distribuição de direitos, bens e oportunidade de uma comunidade deve demonstras igual preocupação com o destino de cada vida. Sem mais delongas, fica nítida a violação desse princípio pelo uso da tortura, na medida em que torturar alguém significa tratá-lo como inferior, humilhá-lo da forma mais cruel, retirando-lhe toda a dignidade e, assim, não lhe reconhecer como ser humano (DWORKIN, 2011, p. 336). Como se falar em igual consideração por toda vida humana,

12 Dentre eles se incluem: 0 art. $5^{\circ}$ da Declaração Universal de Direitos Humanos; 0 art. $7^{\circ}$ do Pacto Internacional sobre Direitos Civis e Políticos; os arts. $2^{\circ}$ e 16 da Convenção contra a tortura e outro tratamentos ou penas cruéis, desumanos ou degradantes (ONU); art. 3 da Convenção Europeia dos Direitos do Homem; art. $5^{\circ}$ da Convenção Americana de Direitos Humanos.

13 UN COMMITEE AGAINST TORTURE. General Comment 2: Implementation of Article 2 by States Parties. In: Compilation of General Comments and General Recommendations Adopted by Human Rights Treaty Bodies, 2007. Disponivel em: http://www.refworld.org/docid/47ac78ce2.html. Acesso em: 10 abr. 2017.

14 AMNESTY INTERNATIONAL. Torture in 2014: 30 years of broken promises, 13 mai. 2014, p. 6 e 10. Disponivel em: https://www.amnesty.org/en/documents/ACT40/004/2014/en/. Acesso em: 5 mar. 2017. 
quando, em prol de certos interesses coletivos, degrada-se aquela vida através da tortura? Não há definitivamente igual consideração pela vida da vítima de tortura, cuja dignidade é violada da forma mais atroz. Dessa forma, tais mecanismos não devem ser utilizados à todo custo, pois "que tipo de vitória teríamos se o terrorismo fosse derrotado ao custo do sacrífico de nossos valores democráticos?" 15 .

Além disso, utilizar-se de mecanismos de tortura traduz um ato deplorável de demonstração de poder e subjugação, no qual o torturador consegue não só controlar a sua vítima, mas até mesmo destruir completamente a sua autonomia, liberdade e o seu poder de decisão (DWORKIN, 2006, p. 38). A habilidade da vítima de sopesar os benefícios e malefícios daquela decisão é destruída, sendo impossível raciocinar devido ao volume de dor insuportável sofrida, reduzindo-a, portanto, a um animal (DWORKIN, 2011, p. 337). Assim, quando a tortura é utilizada para obter informaçóes que não seriam repassadas pelo indivíduo no exercício de algum nível mínimo de autonomia, ela fere explicitamente o segundo princípio da dignidade humana. Da mesma forma, a tortura utilizada contra inimigos políticos, tipicamente utilizada em sistemas ditatoriais, pelo simples fato de suas opiniôes políticas serem opostas às governamentais, também fere o segundo princípio da dignidade (DWORKIN, 2011, p. 336). Isso porque, segundo esse princípio, deve-se ter igual respeito pela responsabilidade pessoal de cada um, de tal forma que se reconheça aquele indivíduo como pessoa, dotada de autonomia suficiente para tomar as suas decisóes, bem como se reconheça a sua independência ética (DWORKIN, 2011, p. 205), para fazer seus juízos individuais de valor.

Essa interpretação dos dois princípios da dignidade humana demonstra claramente que o direito de ser torturado é um trunfo contra uma ação coletiva benéfica, uma vez que as exigências trazidas por esses dois princípios, igual consideração pela vida humana e igual respeito pela responsabilidade pessoal, impedem que seja permitido o uso de mecanismos de tortura, por mais que o seu uso aumente o bem-estar geral. As pessoas têm, assim, o direito de não serem torturadas, em respeito aos dois princípios da dignidade (DWORKIN, 2006, p. 36).

Desse modo, por mais que, em uma perspectiva utilitarista, a tortura nesses casos pudesse trazer um resultado benéfico para um maior número de pessoas (a prisão de um traficante que prejudica a vida em uma comunidade, a localização de uma bomba ou a prevenção de um ataque terrorista), sacrificar esse direito individual de não ser torturado seria um ato tão grave, que seria moralmente errado fazê-lo (DWORKIN, 2006, p. 31). Nesse sentido, Dworkin (2006, p. 28) afirma que não cabe, nos casos de direitos como esse, usar a metáfora do sopesamento de interesses, na medida em que esses direitos devem ser respeitados, independentemente das razóes que justificariam a sua violação. Fica claro, portanto, que o direito de não ser torturado realmente é um direito político. Mas seria apenas isso ou também um direito humano?

Subsequentemente, é necessário analisar se o direito de não ser torturado evoca o direito a uma atitude, qual seja, o direito de ser tratado como um ser humano cuja a dignidade importa de maneira fundamental (DWORKIN, 2011, p. 335). Como já ficou mais que comprovado, os atos de tortura violam cabalmente a dignidade humana, logo, o direito de não ser torturado evoca diretamente o direito a ser tratado como um ser humano,

15 SUPREME COURT OF CANADA. Suresh v. Canada (Minister of Citizenship and Immigration), File n 27790, 2002 SCC 1, 11 jan. 2002. Disponivel em: https://scc-csc.lexum.com/scc-csc/scc-csc/en/1937/1/ document.do. Acesso em: 15 mar. 2017. 
respeitando a sua dignidade intrínseca. Isso significa que praticar tortura é uma afronta à importância da dignidade humana e fazê-lo é tratar alguém não como ser humano, mas como um animal, na medida em que retira a capacidade racional daquela vítima, restringindo completamente sua liberdade decisória.

Não obstante, o governo estadunidense no pós-11 de setembro de 2001, ciente da incompatibilidade do uso de mecanismos de tortura com o sistema jurídico americano, sistematicamente torturou e continua a torturar supostos suspeitos de terrorismo fora do seu território, nos chamados black sites da CIA ou em Guantánamo, como forma de garantir a inaplicabilidade dos direitos fundamentais estadunidentes. Por sua vez, em Rasul v. Bush ${ }^{16}$, a Suprema Corte dos EUA decidiu que os presos detidos na base de Guantánamo têm o direito de requerer habeas corpus às cortes dos EUA, para rever a legalidade de suas prisóes. Em Hamdan v. Rumsfeld ${ }^{17}$, a Suprema Corte declarou a inconstitucionalidade da criação de Tribunais Militares pelo governo Bush, por não falta de autorização do Congresso, e dos seus procedimentos de julgamento, por violarem o direito militar estadunidente e as Convençôes de Genebra. Em contrapartida, o Congresso aprovou o Military Commissions Act $2006^{18}$, autorizando o Presidente a criar esses Tribunais e restringindo o uso de habeas corpus e do acesso dos prisioneiros às cortes federais americans. Por fim, em Boumediene v. Bush ${ }^{19}$, a Suprema Corte reafirmou a sua jurisdição para julgar os habeas corpus de prisioneiros do governo americano fora do território nacional e declarou inconstitucionais os dispositivos legais que restringiam o seu uso. Os precedentes jurisprudenciais fixados nesses três casos deixam claro que a jurisdição americana abarca também as prisóes em Guantánamo e nos black sites da CIA, pois fazem parte do território americano, de tal forma que a prática de tortura pelo governo americano é proibida não apenas no âmago do seu território, mas também fora dele, por violar, obviamente, o direito internacional e, sobretudo, a Constituição dos EUA.

A tortura demonstra um completo ato de desprezo pela dignidade humana e seria completamente inadmíssivel e impensável se alegar um ato de engano em casos de tortura. Como Dworkin (2011, p. 335-336) esclarece, não basta que um governo alegue ter agido de boa-fé, é preciso que a sua argumentação se baseie em alguma interpretação possível dos dois princípios da dignidade. No caso da tortura, náo é possível haver qualquer interpretação plausível que a justifique com base na dignidade humana. Dworkin (2011, p. 336) até mesmo reconhece que, nos casos de direitos humanos mais básicos, que é o caso do direito de não ser torturado, não existe alegação plausível de engano, pois a violação é tão clara, que só pode se tratar de um ato de desprezo. A prática de atos de tortura demonstra inequivocamente o completo desprezo pela vida humana (DWORKIN, 2006, p. 44), sendo, portanto, inegável a natureza de direito humano do direito de não ser torturado.

16 US SUPREME COURT. Rasul v. Bush, 542 U.S 466, 28 jun. 2004. Disponivel em: https://supreme.justia. com/cases/federal/us/542/466/. Acesso em: 18 jun. 2017.

17 US SUPREME COURT. Hamdan v. Rumsfeld, 548 U.S 557, 29 jun. 2006. Disponivel em: https://supreme. justia.com/cases/federal/us/548/557/. Acesso em: 18 jun. 2017.

18 US CONGRESS. Military Commissions Act 2006. 109th Congress, S. 3930, 16 out. 2006. Disponivel em: https://www.congress.gov/bill/109th-congress/senate-bill/3930. Acesso em: 18 jun. 2017.

19 US SUPREME COURT. Boumediene v. Bush, 553 U.S 723, 12 jun. 2008. Disponivel em: https://supreme. justia.com/cases/federal/us/553/723/opinion.html. Acesso em: 18 jun. 2017. 


\section{CONSIDERAÇÕES FINAIS}

Como foi demonstrando, a concepção de Dworkin de direitos humanos, baseada na noção de trunfos e nos dois princípios da dignidade humana, contribui muito para a consolidação de uma teoria sólida de proteção dos direitos humanos. Tal teoria reconhece a dimensão moral e simbólica dos direitos humanos, de tal forma que a positivação funciona como estímulo à mudança de cultura e dá suporte político, social e moral para isso. A aplicação desse conceito à proibição absoluta do uso de tortura contribui para determinar que não é moralmente (e nem juridicamente) viável a sua relativização.

Bem verdade, as situaçóes excepcionais desenhadas para se justificar o uso de mecanismos de tortura são cenários muito irreais, que dificilmente ocorreriam e, mesmo que ocorressem, a relativização da proibição absoluta da tortura resulta na disseminação da prática. Permitir alguns níveis e em algumas condiçóes a tortura é abrir a possibilidade para o abuso e recorrência da prática, na medida em que o controle do seu uso seria impraticável, transformando-a em uma atividade legítima. Ademais, quão hipócrita seria a oposição dos países democráticos ao uso de métodos de tortura por ditaduras e tiranias, quando, na verdade, fazem o mesmo nas supostas situaçóes de risco?

A tortura não é uma arma adequada para a luta contra o terrorismo nem contra o narcotráfico, pois apenas estimula o ódio entre naçóes e mantém o ciclo vicioso de violência, que só pode ser quebrado com o respeito aos direitos humanos. Estados democráticos devem lutar contra o terrorismo e o narcotráfico sem comprometer os seus valores básicos; esse deve ser o corolário da democracia: o desenvolvimento contínuo das proteçóes dos direitos humanos acima de quaisquer outros interesses, de tal forma que eles atuem como trunfos contra ações políticas coletivas.

\section{REFERÊNCIAS}

AMNESTY INTERNATIONAL. Torture in 2014: 30 years of broken promises, 13 mai. 2014, p. 6 e 10. Disponível em: https://www.amnesty.org/ en/documents/ACT40/004/2014/en/. Acesso em: 5 mar. 2017.

BEITZ, Charles. The Idea of Human Rights. Oxford: Oxford University Press, 2009.

CLÍNICA DE DIREITOS HUMANOS DA UFMG. Recomendação da Clínica de Direitos Humanos da UFMG sobre o PL no 5555/2013. Universidade Federal de Minas Gerais: Belo Horizonte, 2015.

CONSElHO DA EUROPA. Convenção Europeia dos Direitos do Homem. 04 nov. 1950. Disponível em: http://www.echr.coe.int/Documents/Convention_POR.pdf. Acesso em: 18 abr. 2017.

COURT OF KING'S BENCH. Somerset v Stewart, 177298 ER 499, 14 mai. 1772. Disponível em: http://www.commonlii.org/int/cases/EngR/1772/57.pdf. Acesso em: 15 jun. 2017.

DWORKIN, Ronald. Is democracy possible here? Principles for a New Political Debate. Princeton: Princeton University Press, 2006.

. Justice for Hedgehogs. The Belknap Press of Harvard University Press: Cambridge, 2011. 
O Império do Direito. São Paulo: Martins Fontes, 1999.

Response. In: Symposium: Justice for Hedgehogs: A Conference on Ronald

Dworkin's Forthcoming Book. Boston University Law Review, v. 90, n. 2, p. 10591087, 2010.

. Rights as Trumps. In: WALDRON, Jeremy (Ed). Theories of Rights. Oxford: Ox- ford University Press, 1985.

EUROPEAN COMMISSION ON HUMAN RIGHTS. Greek Case, Commission Report of 5 November 1969, Yearbook 12, 15 abr. 1970. Disponível em: hudoc.echr.coe. int/app/conversion/pdf/?library=ECHR\&id=001-73020\&filename=001-73020. pdf. Acesso em: 20 abr. 2017

GRIFFIN, James. Human rights and the autonomy of International Law. In: BESSON, Samantha; TASIOULAS, John (Eds). The Philosophy of International Law. Oxford: Oxford University Press, 2010.

INTERNATIONAL LABOUR ORGANIZATION. ILO Global Estimate of Forced Labour: Results and methodology. ILO Publications: Suíça, 2012. Disponível em: http://www.ilo.org/global/topics/forced-labour/publications/WCMS_182004/lang-en/index.htm. Acesso em: 17 jun. 2017.

MACLEOD, Alistair. Rawls's Narrow Doctrine of Human Rights. In: MARTIN, Rex; REIDY, David (Eds). Rawls's Law of Peoples: a realistic utopia?. Oxford: Blackwell, 2006.

NONHUMAN RIGHTS PROJECT. Portal da organização não-governamental "Nonhuman Rights Project". Disponível em: https://www.nonhumanrights.org/. Acesso em: 19 jun. 2017.

NOWAK, Manfred. What practices constitute torture? US and UN Standards. Human Rights Quaterly, v. 28, p. 809-841, 2006.

ORGANIZAÇÃO DOS ESTADOS AMERICANOS. Convenção Americana de Direitos Humanos. 22 nov. 1969. Disponível em: https://www.cidh.oas.org/ basicos/portugues/c.convencao_americana.htm. Acesso em: 30 abr. 2017.

ORGANIZAÇÃO DAS NAÇÓES UNIDAS. Convençáo contra a tortura e outros tratamentos ou penas cruéis, desumanos ou degradantes, 10 dez. 1984. Disponível em: http://www.ohchr.org/Documents/ProfessionalInterest/cat.pdf. Acesso em: 15 mar. 2017.

. Declaraçáo Universal de Direitos Humanos. 10 dez. 1948. Disponível em: http://www.ohchr.org/EN/UDHR/Documents/UDHR_Translations/por.pdf. Acesso em: 10 abr. 2017.

Pacto Internacional sobre Direitos Civis e Políticos. 10 dez. 1966. Disponível em: http://www.ohchr.org/Documents/ProfessionalInterest/ccpr.pdf. Acesso em: 12 abr. 2017.

RAWLS, John. The Law of Peoples. Cambridge: Harvard University Press, 1999.

RAZ, Joseph. Human rights without foundations. In: BESSON, Samantha; TASIOULAS, John (Eds). The Philosophy of International Law. Oxford: Oxford University Press, 2010. 
SLOANE, Robert. Human Rights for Hedgehogs? Global Value Pluralism, International Law, and Some Reservations of the Fox. In: Symposium: Justice for Hedgehogs: A Conference on Ronald Dworkin's Forthcoming Book, Boston University Law Review, v. 90, n. 2, p. 975-1009, 2010.

SOARES, Fabiana de Menezes. Mulheres substantivas - Olympe de Gouges e Marietta Baderna: o papel subversivo das artes no contexto dos direitos humanos em movimento, Revista de Estudos Legislativos, n. 10, p. 15-87, 2016.

SUSSMAN, David. What's wrong with Torture?. Philosophy \& Public Affairs, v. 33, n. 1, p. 1-33, 2005.

SUPREME COURT OF CANADA. Suresh v. Canada (Minister of Citizenship and Immigration), File no 27790, 2002 SCC 1, 11 jan. 2002. Disponível em: https://scccsc.lexum.com/scc-csc/scc-csc/en/1937/1/document.do. Acesso em: 15 mar. 2017.

UN COMMITTEE AGAINST TORTURE. General Comment 2: Implementation of Article 2 by States Parties. In: Compilation of General Comments and General Recommendations Adopted by Human Rights Treaty Bodies, 2007. Disponível em: http://www.refworld.org/docid/47ac78ce2.html. Acesso em: 10 abr. 2017.

Hajrizi Dzemajl v. Yugoslavia, Communication no 161/2000, U.N. Doc. CAT/C/29/D/161/2000, decisão de 21/11/2002. Disponível em: http:// hrlibrary.umn.edu/cat/decisions/161-2000.html. Acesso em: 15 mai. 2017.

UNITED NATIONS OFFICE ON DRUGS AND CRIME. Global Report on Trafficking in Persons 2016. United Nations: Nova Iorque, 2016, p. 6. Disponível em: https:// www.unodc.org/documents/data-and-analysis/glotip/2016_Global_Report_on_ Trafficking_in_Persons.pdf. Acesso em: 17 jun. 2017.

US CONGRESS. Military Commissions Act 2006. 109 th $^{\text {th }}$ Congress, S. 3930, 16 out. 2006. Disponível em: https://www.congress.gov/bill/109th-congress/senate-bill/3930. Acesso em: 18 jun. 2017.

US SUPREME COURT. Boumediene v. Bush, 553 U.S 723, 12 jun. 2008. Disponível em: https://supreme.justia.com/cases/federal/us/553/723/opinion.html. Acesso em: 18 jun. 2017.

. Hamdan v. Rumsfeld, 548 U.S 557, 29 jun. 2006. Disponível em: https://supreme. justia.com/cases/federal/us/548/557/. Acesso em: 18 jun. 2017.

. Rasul v. Bush, 542 U.S 466, 28 jun. 2004. Disponível em: https://supreme.justia. com/cases/federal/us/542/466/. Acesso em: 18 jun. 2017.

WEST, Robin. Rights, Harms, and Duties: A Response to Justice for Hedgehogs. In: Symposium: Justice for Hedgehogs: A Conference on Ronald Dworkin's Forthcoming Book, Boston University Law Review, v. 90, n. 2, p. 819-837, 2010.

\section{Caroline Stéphanie Francis dos Santos Maciel}

carolinedossantos3@gmail.com

Bacharela em Direito pela Universidade Federal de Minas Gerais (UFMG). Mestra em Direito pela UFMG, com bolsa do CNPq. Doutoranda em Direito no Programa de PósGraduação da Faculdade de Direito da UFMG. Advogada vinculada à Divisão de Assistência Judiciária (DAJ) em Direito Tributário e Civil. 


\section{Fabiana de Menezes Soares}

fabiana.demenezes@terra.com.br

Graduada em Direito pela Universidade Federal de Minas Gerais (UFMG) Mestra em Direito pela UFMG. Doutora em Direito pela UFMG. Professora Associada II da Faculdade de Direito da UFMG, nos cursos de Graduação e Pós-graduação. Coordenadora do grupo de pesquisa Observatório para a Qualidade da Lei, certificado pelo CNPq, e do Núcleo de Inclusão Digital da Clínica de Direitos Humanos da Faculdade de Direito da UFMG. 